MLM-3785

UC-700

\title{
Sequential Shock Induced Switch Tests for Eglin Air Force Base
}

Russell D. Cech

Issued: August 11, 1994

\section{MOUND}

operated by

EERE MOUND APPLIED TECHNOLOGIES

P.O. Box 3000, Miamisburg, Ohio $45343-3000$

for the

U. S. DEPARTMENT OF ENERGY

Contract No. DE-AC04-88DP43495 


\section{Contents}

Abstract $\ldots \ldots \ldots \ldots \ldots \ldots \ldots \ldots \ldots \ldots \ldots \ldots \ldots \ldots \ldots \ldots \ldots \ldots$

Experimental Setup $\ldots \ldots \ldots \ldots \ldots \ldots \ldots \ldots \ldots \ldots \ldots \ldots \ldots \ldots$

Test Results $\ldots \ldots \ldots \ldots \ldots \ldots \ldots \ldots \ldots \ldots \ldots \ldots \ldots \ldots \ldots \ldots \ldots \ldots$

Test Series 1: 600- and 4000-Volt Potential .............. 4

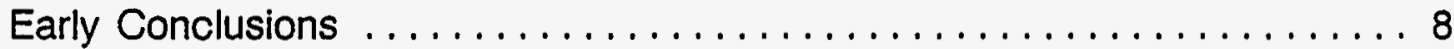

Redesigned Tests $\ldots \ldots \ldots \ldots \ldots \ldots \ldots \ldots \ldots \ldots \ldots \ldots \ldots \ldots \ldots \ldots \ldots$

Test Series 2: Effect of a Cover Coat $\ldots \ldots \ldots \ldots \ldots \ldots \ldots \ldots \ldots \ldots$

Early Conclusions ............................... 10

Test Series 3: Effect of No Ground on Second Switch . . . . . . . . . . 11

Early Conclusions .............................. 12

Test Series 4: Effect of No Ground on Third Switch . . . . . . . . . . . . 12

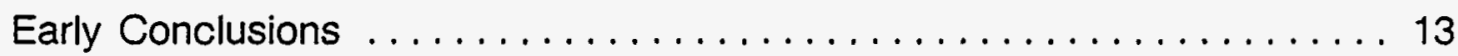

Test Series 5: Effect of Kapton Removal Between $S 1$ and $S 2 \ldots \ldots \ldots 14$

Early Conclusions . . . . . . . . . . . . . . . . . . . . . . . . . . 14

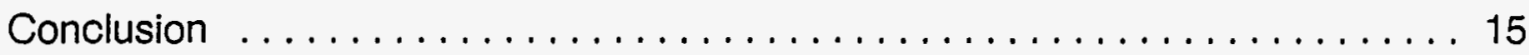

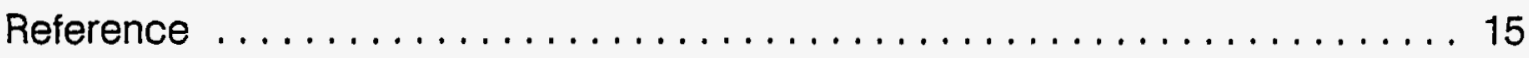

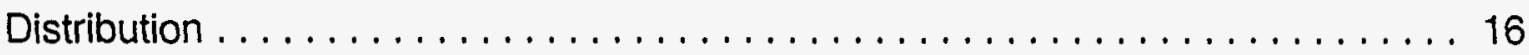




\section{DISCLAIMER}

This report was prepared as an account of work sponsored by an agency of the United States Government. Neither the United States Government nor any agency thereof, nor any of their employees, make any warranty, express or implied, or assumes any legal liability or responsibility for the accuracy, completeness, or usefulness of any information, apparatus, product, or process disclosed, or represents that its use would not infringe privately owned rights. Reference herein to any specific commercial product, process, or service by trade name, trademark, manufacturer, or otherwise does not necessarily constitute or imply its endorsement, recommendation, or favoring by the United States Government or any agency thereof. The views and opinions of authors expressed herein do not necessarily state or reflect those of the United States Government or any agency thereof. 


\section{DISCLAIMER}

Portions of this document may be illegible in electronic image products. Images are produced from the best available original document. 


\section{Abstract}

Tests were performed at EG\&G Mound Applied Technologies to investigate the effect of using the tangential shock wave from detonating Extex explosive to cause shock conduction of a Kapton dielectric. Two voltages (600 and 4000) were switched from a $600 \mathrm{pF}$ capacitor. Timing between four shock switches and four pin switches was found and compared during a single detonation event. Electrical conduction was observed between shock switches and the current paths were found.

This work was funded by Eglin Air Force base through DOE/AL by contract number DE-AC04-89DP43495.

\section{Experimental Setup}

A series of tests were performed to evaluate the effect of a tangential shock on a series of Kapton-based, shock-conductive switches. The vehicle chosen for the first series of tests was the device depicted in Figure 1, a sequential switch in which a Mound-built MC1957A Exploding Bridge Wire (EBW) detonator was used to detonate a track of Extex (XTX-8003) extrudable explosive. Extex, which contains $80 \%$ PETN by weight and $20 \%$ RTV (Sylgard 182) silicone rubber binder, is manufactured by Mason Hanger at the Pantex Plant.

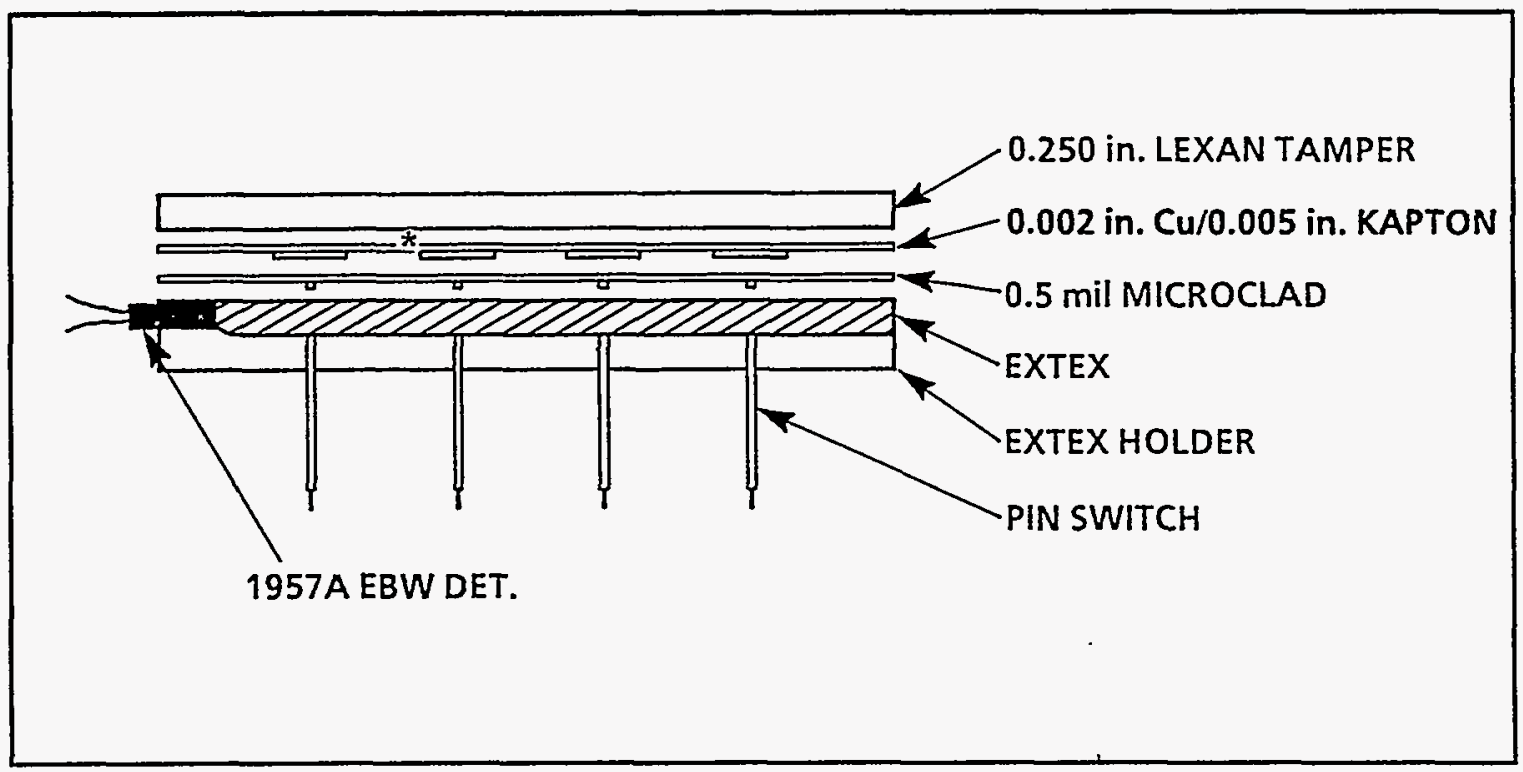

Figure 1 - Cross section of Version 4 test device. Leading edge of second conductor marked with an asterisk. 
To set up for the test, a 0.250 -in. ball endmill was used to machine a track into the ABS plastic Extex holder to a total depth of 0.250 in. Then four 0.022 -in. diameter holes, spaced 1 in. apart, were machined into the Extex holder for the four Dynasen pin switches. These pin switches extended into the Extex 0.010 in.

The sequential switches in this test series used two conductors, the first of which was a 0.010 -in. wide by 0.000175 -in. thick copper conductor adjacent to the Extex track. These conductors were etched from a raw stock of Microclad material and included features that allowed precision alignment of the conductors to the $0.022-i n$. diameter Dynasen pin switches.

The second conductor was $0.500 \mathrm{in}$. wide and 0.002 in. thick. Individually fabricated from 0.002 -in. thick copper foil, it was placed on 0.005 -in. thick pressure sensitive tape with a center line to center line spacing of $1 \mathrm{in}$.

The two conductors were separated by a single layer of 0.0005 -in. thick Kapton (polyamide film). This entire assembly was held tightly to the Extex track with a 0.250 -in. thick Lexan tamper. Prior to Extex detonation, an electrical potential was applied to the two conductors and maintained by the Kapton layer that electrically insulated them.

Previous tests performed by Mound and others indicate that shock pressures developed during the detonation of explosives cause Kapton to transition from an electrical insulator to an electrical conductor. This transition was monitored by a CVT (Current Viewing Transformer) and its timing found by recording the start of the current through the switch. A 500-pF capacitor was charged to a given potential for each of the shock switches in the setup. Each capacitor was isolated from the other by a 5 -megohm resistor.

\section{Test Results}

\section{Test Series 1: 600- and 4000-Volt Potential}

The first test series involved a matrix of four tests that used two voltages $(600$ and 4000 volts) and two polarities (ground on H.E. side and ground on opposite side). During the first shot, a 600-volt potential was applied across the four Kapton shock switches as shown in Figure 1. The timing results are shown graphically in Figure 2 and also given in Table 1. The first two data points on the graph are higher than the rest because they include the function time of the MC1957A EBW detonator. The important thing to note here is that the tangential shock from the detonating Extex consistently closes the Kapton shock switch, as shown by the close correlation between the graphs of the pin and shock switches. The largest time difference observed in the test was $28 \mathrm{~ns}$ between the pin and shock switch closure. In one case, timing was less than $1 \mathrm{~ns}$. 


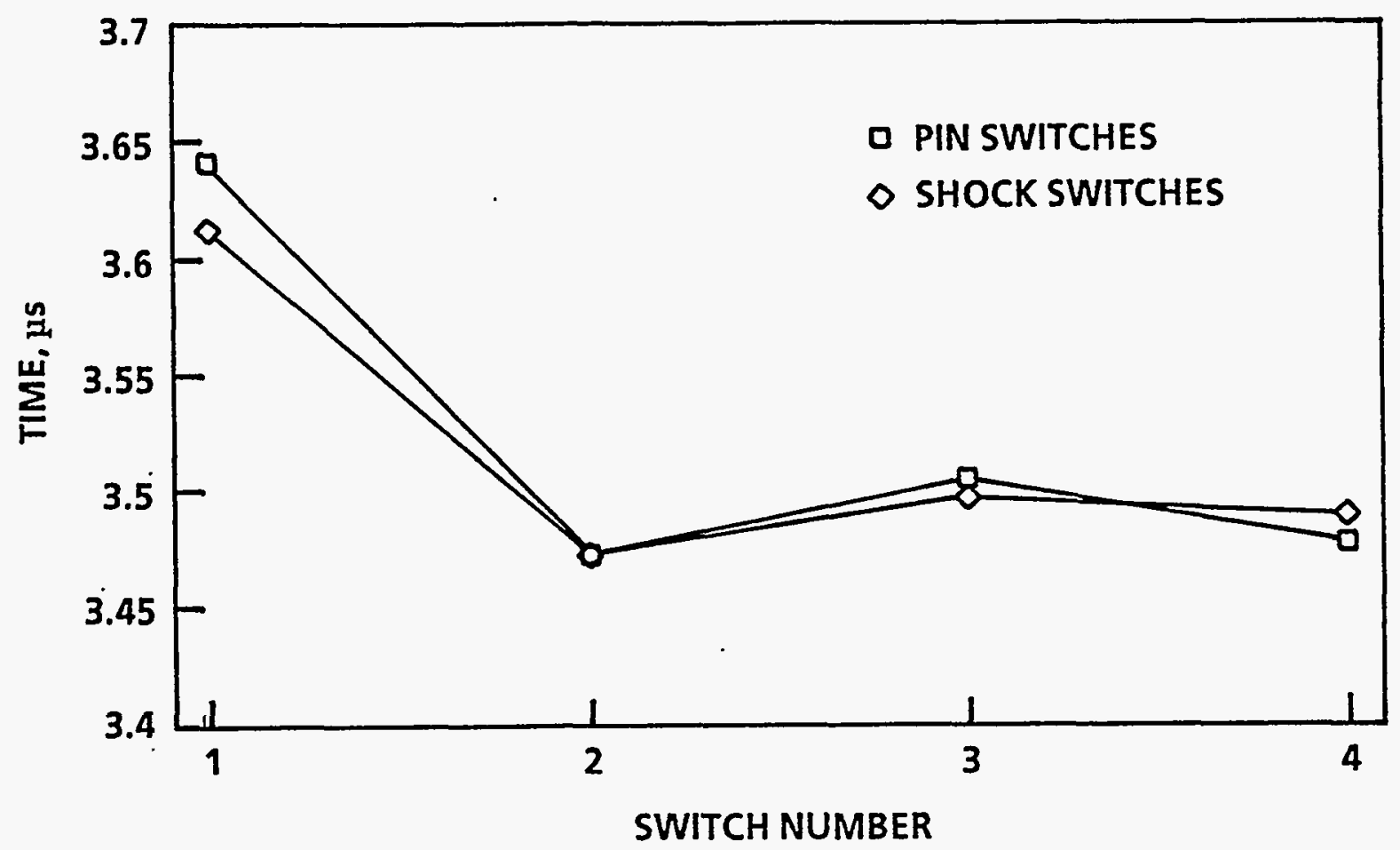

Figure 2 - Timing between pin and shock switches, 600 volts away from $H . E$.

\section{Table 1 - 600 VOLT POTENTIAL, AWAY FROM H.E.}

Bridge Wire burst to Pin Switch 1

Bridge Wire Burst to Shock Switch 1

Delta $T$

Pin Switch 1 to Pin Switch 2

Shock Switch 1 to Shock Switch 2

Delta $T$

Pin Switch 2 to Pin Switch 3

Shock Switch 2 to Shock Switch 3

Delta $T$

Pin Switch 3 to Pin Switch 4

Shock Switch 3 to Shock Switch 4

Delta $T$
$3.640 \mu \mathrm{s}$

$3.612 \mu \mathrm{s}$

$0.028 \mu \mathrm{s}$

$3.472 \mu \mathrm{s}$

$3.472 \mu \mathrm{s}$

$0.000 \mu \mathrm{s}$

$3.504 \mu \mathrm{s}$

$3.496 \mu \mathrm{s}$

$0.008 \mu \mathrm{s}$

$3.476 \mu \mathrm{s}$

$3.488 \mu \mathrm{s}$

$-0.012 \mu \mathrm{s}$ 
At the time of these tests it was unknown whether the shock pressures of the tangential shock, which are less than half those of a perpendicular shock from a given explosive, would be sufficient to close the switch. R. A. Graham stated "Kapton was found to have a threshold stress for shock-induced switching of about $9 \mathrm{GPa}$ [1]." The results of this test indicate that the tangential shock of Extex must be greater than $9 \mathrm{GPa}$. Also Graham notes an "inherent time delay" of 50 ns. No such time delay was observed in these tests.

In the second shot of this test series, the polarity of the 600 volts applied to the switch was changed so that the ground conductor of the switch was away from the Extex. The polarity change caused no significant difference in the current traces. The worst-case timing difference was $14 \mathrm{~ns}$, but timing in another case was as close as 2 ns. Figure 3 shows the second shot results graphically, with associated times listed in Table 2. Again, no time delay was noted in the Kapton shock-induced switches.

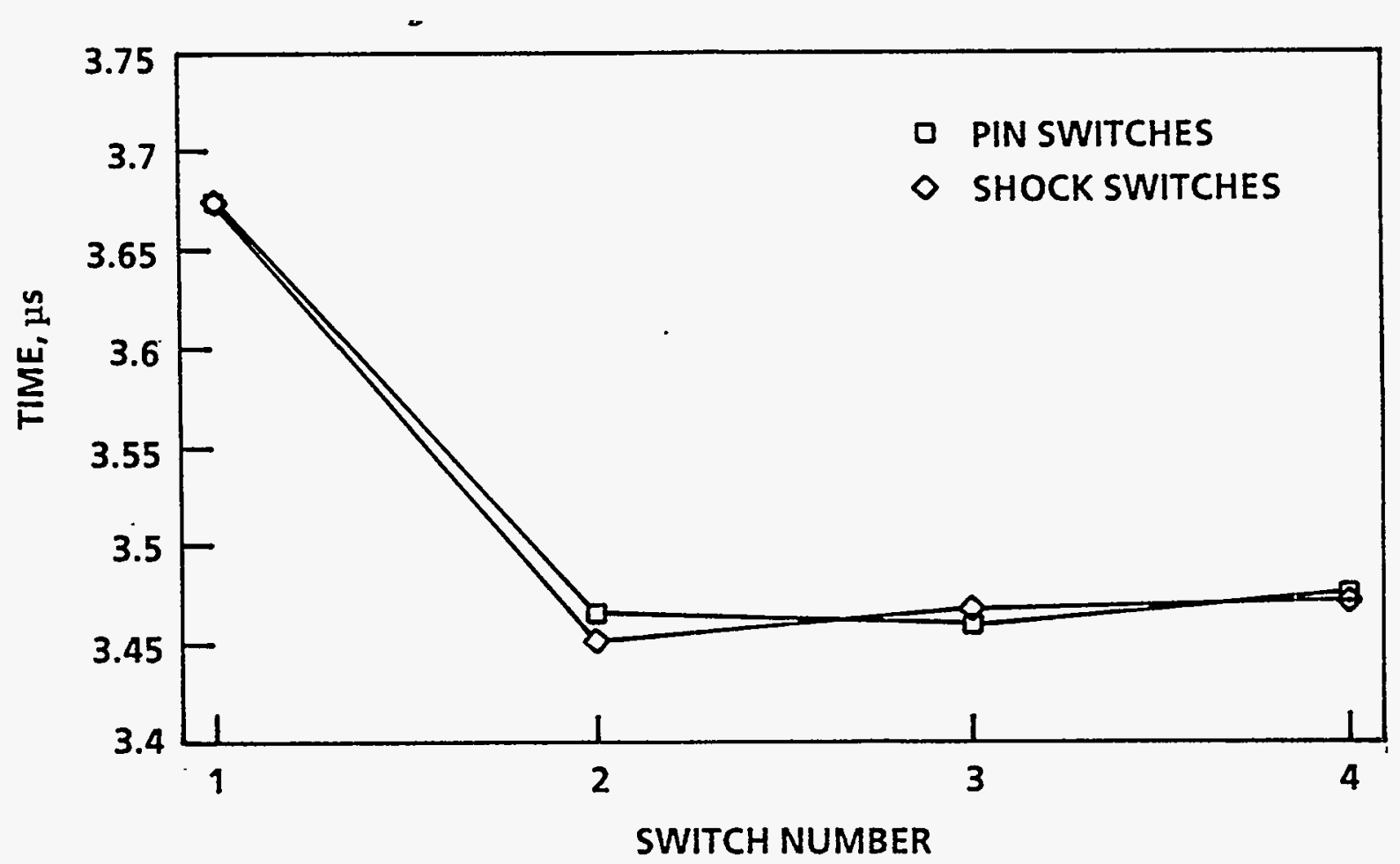

Figure 3 - Timing between pin and shock switches, 600 volts toward $H . E$. 


\section{Table 2 - 600 VOLT POTENTIAL, TOWARD H.E.}

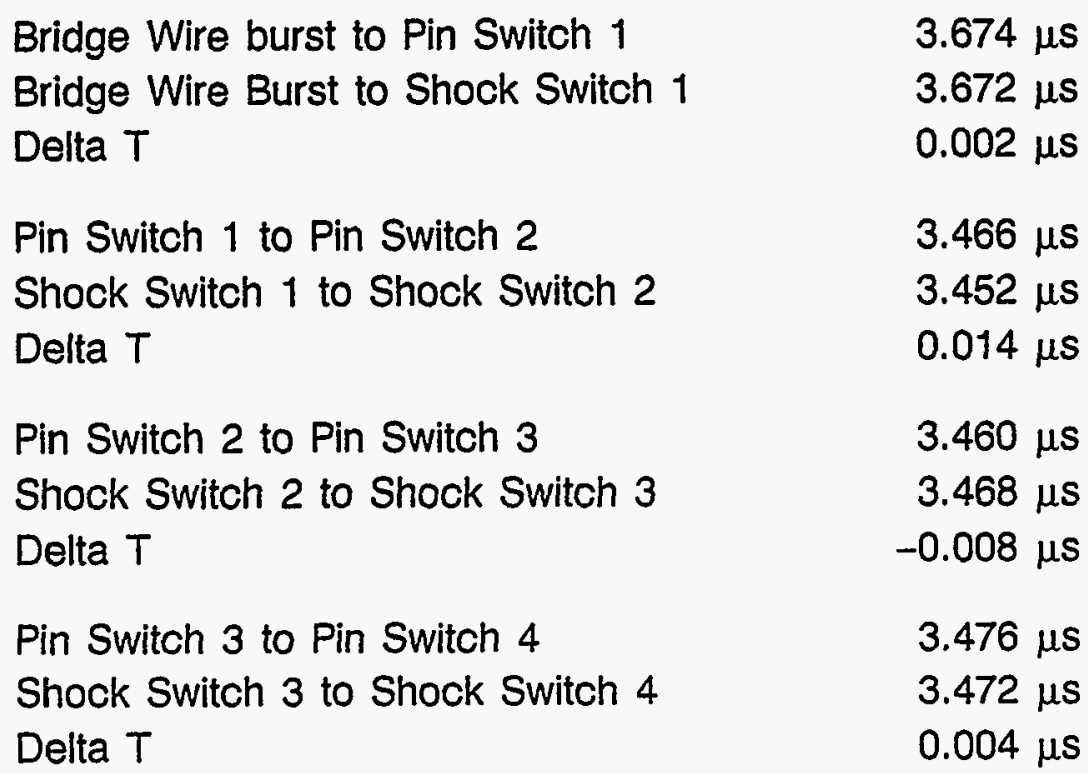

In the third and fourth shots in this test series, the voltage was increased to 4000 volts. The use of higher voltages increased the noise level high enough that meaningful timing was not obtainable. However, the information that was obtained showed the shock switches were closing early. It was believed that the shock was inducing conduction in the Kapton at times corresponding to the arrival of the shock at the leading edge of the 0.500 -in. wide conductor in the second, third, or fourth switch (Figure 1). The current would flow through the shocked Kapton, down the detonation products, and to the ground of the proceeding circuit. For example, after Switch 1 would function, the detonation would continue to the leading edge of the 0.500 -in. conductor on Switch 2. Because the leading edge of Switch 2 is 0.750 in. from Switch 1, in theory it would close $25 \%$ earlier because of the shorter path ( $1.000 \mathrm{in}$. vs $0.750 \mathrm{in}$.). This effect was not noted in the tests at 600 volts, probably because of the lower potential. The next series of tests was designed to further understand the above results. 


\section{Early Conclusions}

The close time correlation between the pin (ionization) switches buried in the Extex and the closure of the Kapton switches indicate that the dielectric breakdown of the Kapton is caused by the shock rather than by some other phenomenon such as burning.

- The polarity of the 600-volt potential did not make a difference.

- Sequential switching at 600 volts was successfully demonstrated.

- Sequential switching at 4000 volts was not successful with this first design. Cross talk between circuits may possibly have been the cause.

- An inherent time delay was not found in the Kapton switches.

- Tangential shock pressures from Extex is high enough to close the switch.

\section{Redesigned Tests}

Because of the concerns and questions that were raised in the first test series, a second group of parts were fabricated. The test device remained the same except for two changes. First, the 0.500 in. by 0.002 in. conductor was replaced with the $0.010 \mathrm{in}$. by $0.000175 \mathrm{in.}$ conductor. This resulted in two conductors, 0.010 in. wide, separated by the 0.0005 in. Kapton. Second, the pin switches were disregarded in order to reduce the number of signals that had to be monitored during the event. The new device is shown in Figure 4. In addition to these changes, the charging circuit (Figure 5) used a voltage divider to monitor the current, rather than the CVT used in the first test series.

\section{Test Series 2: Effect of a Cover Coat}

Two devices were tested, one with and one without a 0.005 in. cover coat of Kapton between the Extex and the adjacent conductor. A potential of 4000 volts was applied the conductors, and the time between the closure of the first and second switch was recorded for each of the two devices:

- with cover coat .......................... $3.515 \mu \mathrm{s}$

n without cover coat ........................3.530 $\mu \mathrm{s}$

Times recorded in the first test series using a CVT compared favorably to the times recorded with the new circuit using voltage dividers. Comparisons of the wave forms indicted no difference between switch function with or without the 0.005 -in. thick Kapton cover coats. This indicates that Kapton shock conductive 
switches may be used at lower shock pressures from tangential shock for high voltage, low current applications such as these.

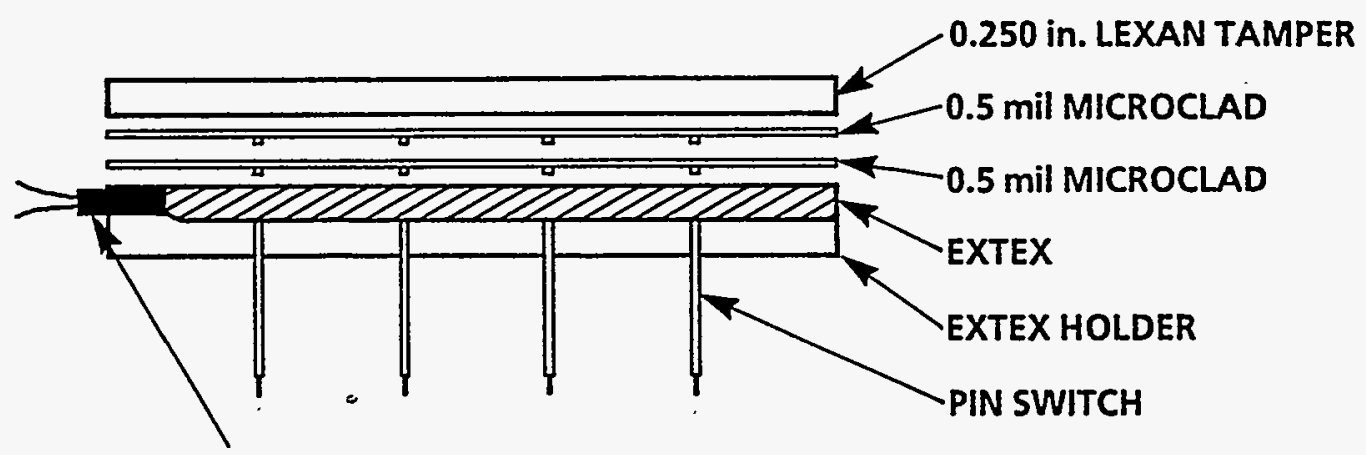

1957A EBW DET.

Figure 4 - Version $B$ test device with second conductor width changed. Pin switches in place, but not monitored.

\section{EXTEX}

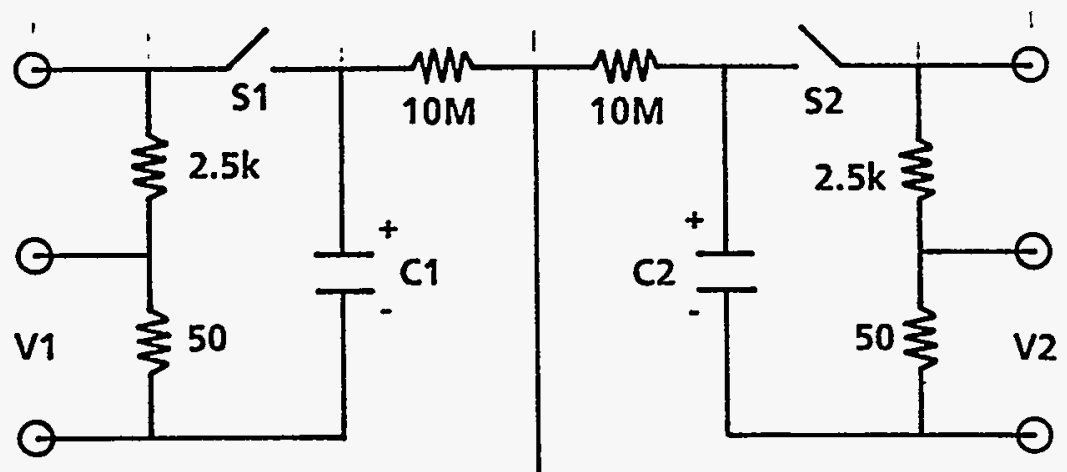

CIRCUIT \#1

CIRCUIT \#2

() VIN

Figure 5 - Charging circuit and Extex track. 
Figure 6 shows a scope trace (500 ns/division) of one of these signals. The upper trace is for Switch 1 (S1) and is the voltage labeled V1 in Circuit 2 of Figure 5. The lower trace of Figure 6 is for Switch 2 (S2) and is the voltage labeled V2 in Circuit 2 of Figure 5. When S1 closes, the upper voltage trace goes off scale and a small amount of noise is shown on the lower trace. When the second switch closes, $3.515 \mu$ s later, the lower trace also goes off scale. The important thing to note here is that the upper trace goes off scale a second time.

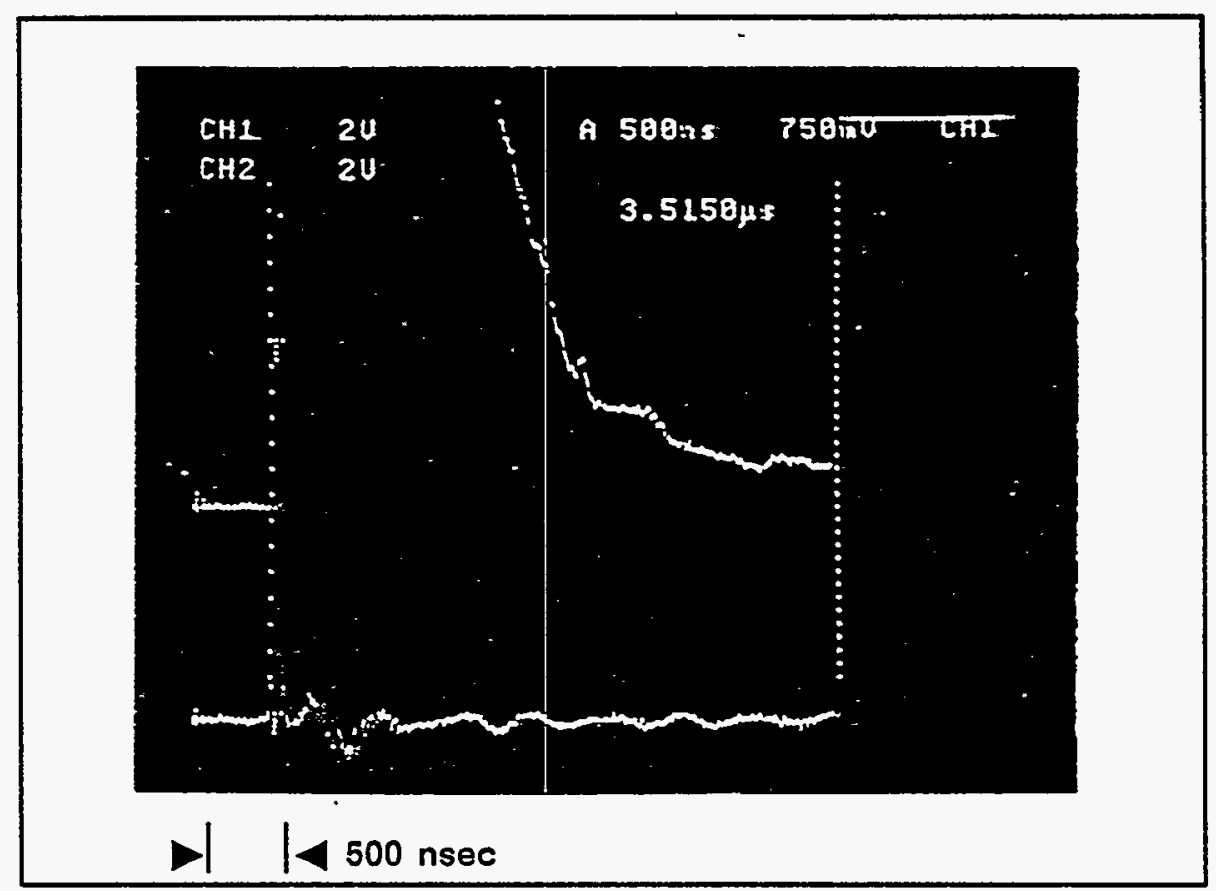

Figure 6 - Typical wave form. Upper trace signal is from Circuit 1, lower is from Circuit 2. Note that both are off scale during second rise.

This can be explained by Figure 7. After $\mathrm{S} 1$ closes, the detonation products (shocked and charred Kapton, ABS and Lexan plastic, and unknown surface effects) are electrically connected to ground thorough Circuit 1 . When the detonation front reaches the second switch, at $t=3.515 \mu \mathrm{s}$, two ground paths exist. The current follows these paths and is recorded as V1 and V2.

\section{Early Conclusions}

- The 4000 volts successfully switched and voltages were monitored.

- Cross talk between switches was again observed.

- First switch closed normally while current from second switch used two ground paths. 


\section{Test Series 3: Effect of No Ground on Second Switch}

Two tests were performed with the ground leg of Circuit 2 not attached to S2. This characterized the current from $\mathrm{C} 2$, which found a path to the ground in Circuit 1. Figure 8 shows the conduction path of S2 through Circuit 1.

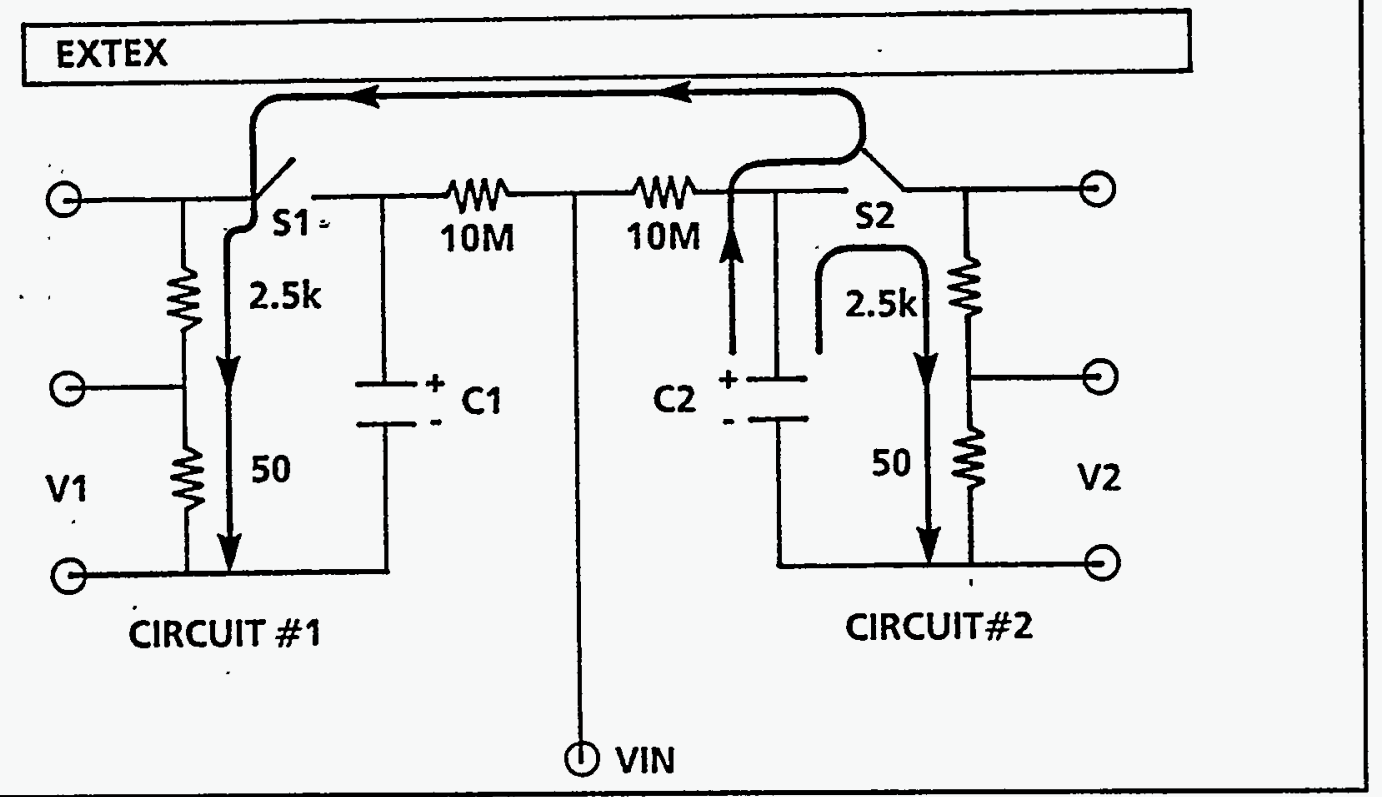

Figure 7 - Path of current flow from C2, picked up as V1 on Circuit 1 and V2 on Circuit 2.

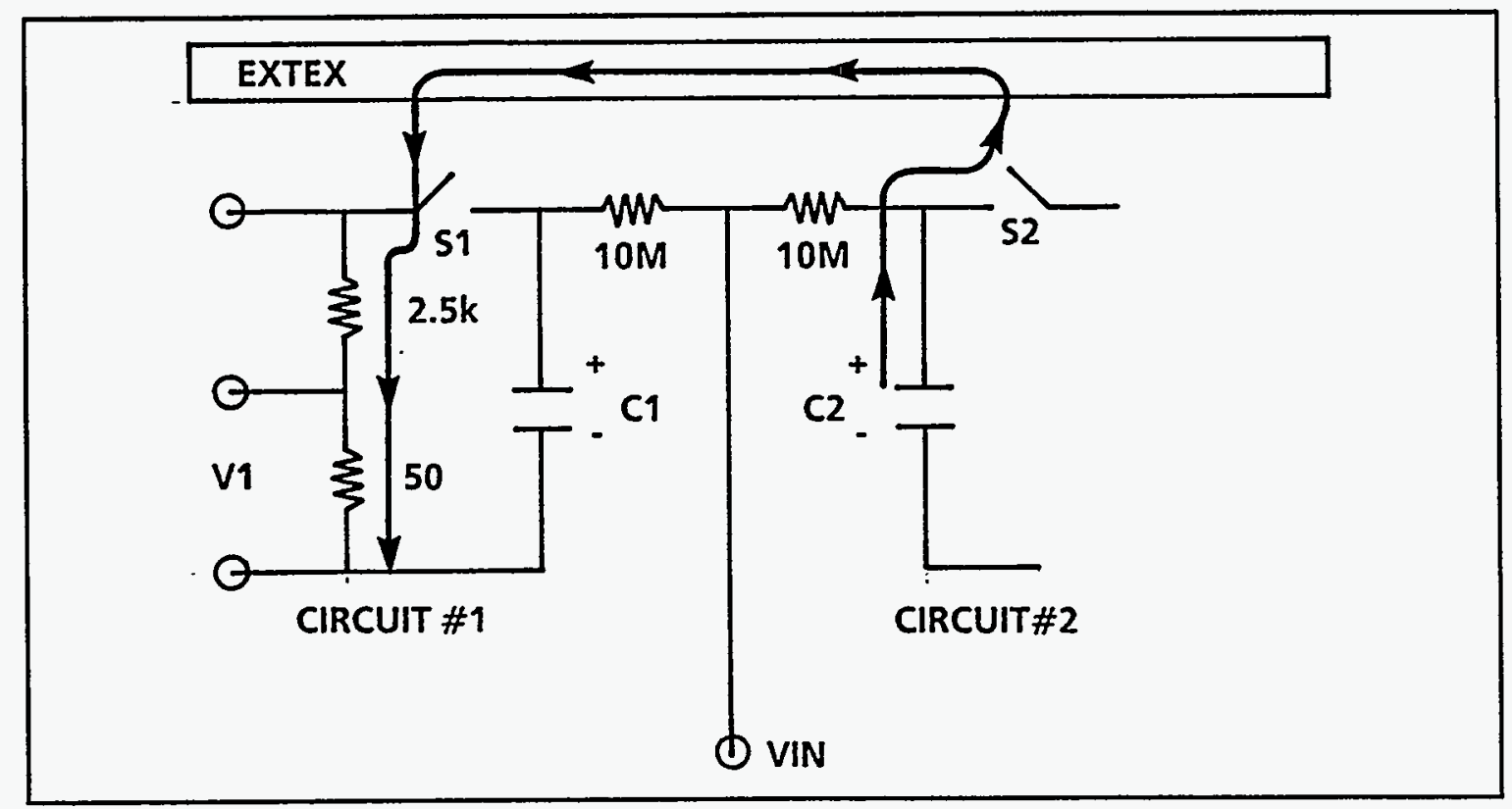

Figure 8 - Path of current when no ground is on $S 2$. 
The trace on the left side of Figure 9 shows the start of V1 from $S 1$ at 50 ns/division. The trace on the right side of Figure 9 shows the start of V1 at 50 ns/division as a result of $S 2$ switching to ground. A higher impedance to ground for $\mathrm{S} 2$ caused a slow rise time, as shown by comparing the two traces.

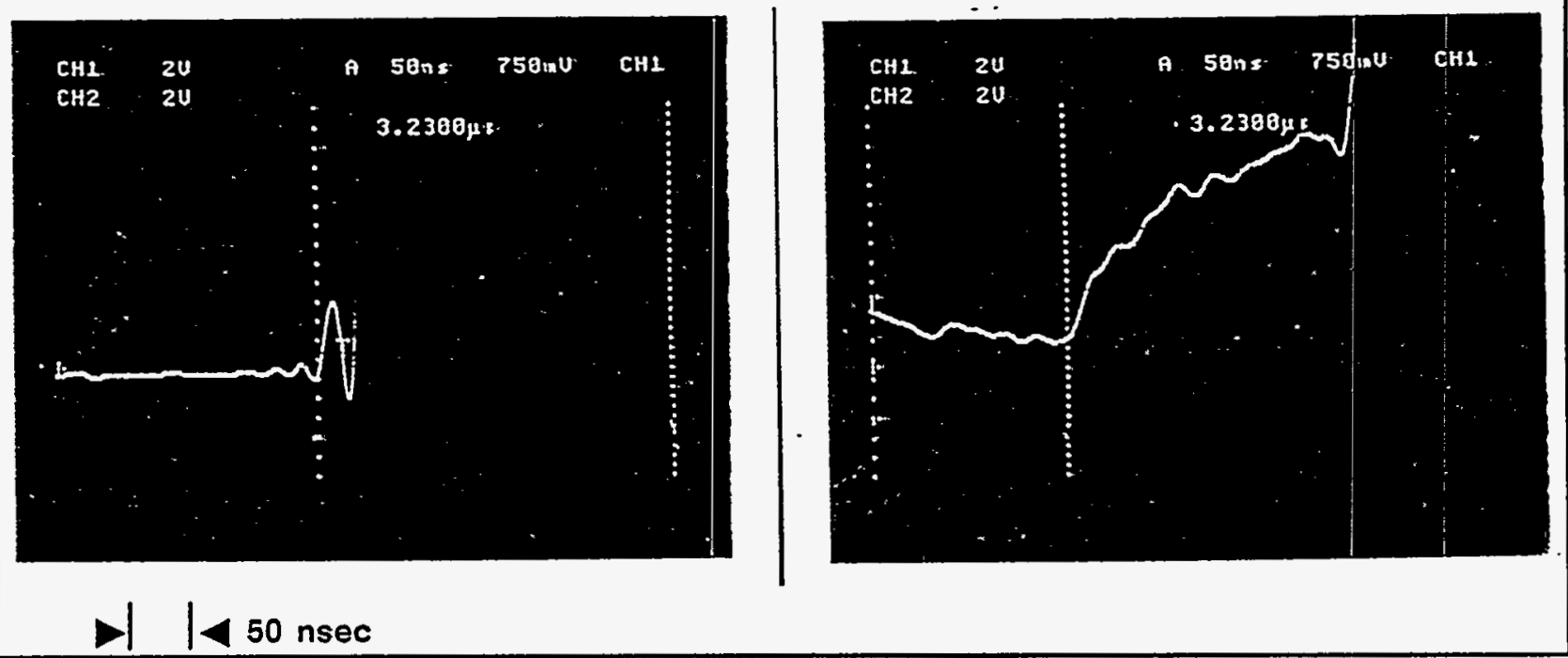

Figure 9 - Electrical data taken from test with the $S 2$ ground removed. The trace in both records is VI (Figure 8). The closure of the first switch caused the signal for VI to increase offscale as seen on the original record reproduced here on the left. The closure of the second switch caused the increase in VI shown in the record on the right.

\section{Early Conclusions}

- Two signals were observed from the system, with one ground at Switch 1.

- The second signal had a slower rise time because of higher impedance.

\section{Test Series 4: Effect of No Ground on Third Switch}

The effect of a longer path to ground (made through the detonation products) was investigated by removing the ground from the third switch. This made Test 4 similar to Test 3 , except that the resulting separation between the ground on the first switch and C3 was now 2 in. instead of 1 in. (Switch 2 was not activated.)

Figure 10 shows two traces from two different shots. The trace on the left is the start of $\mathrm{V} 3$ at $50 \mathrm{~ns} /$ division with the ground attached to $\mathrm{S3}$. The trace on the right is the start of $V 3$ at $50 \mathrm{~ns} /$ division for a second shot without the ground attached. The time between S1 and S3 for the second shot was $6.970 \mu \mathrm{s}$, which is approximately twice the time between $\mathrm{S} 1$ and $\mathrm{S} 2$. Comparison of the two 
traces on Figure 10 shows the slow rise time for the second case as a result of the higher impedance to ground. Figure 11 shows the conduction path of $S 3$ through Circuit 1.

\section{Early Conclusions}

- Two signals were observed when switch spacing was doubled (2 in. apart).

- The function time doubled as the distance doubled.

- The rise time was very slow for the second signal without a direct ground.
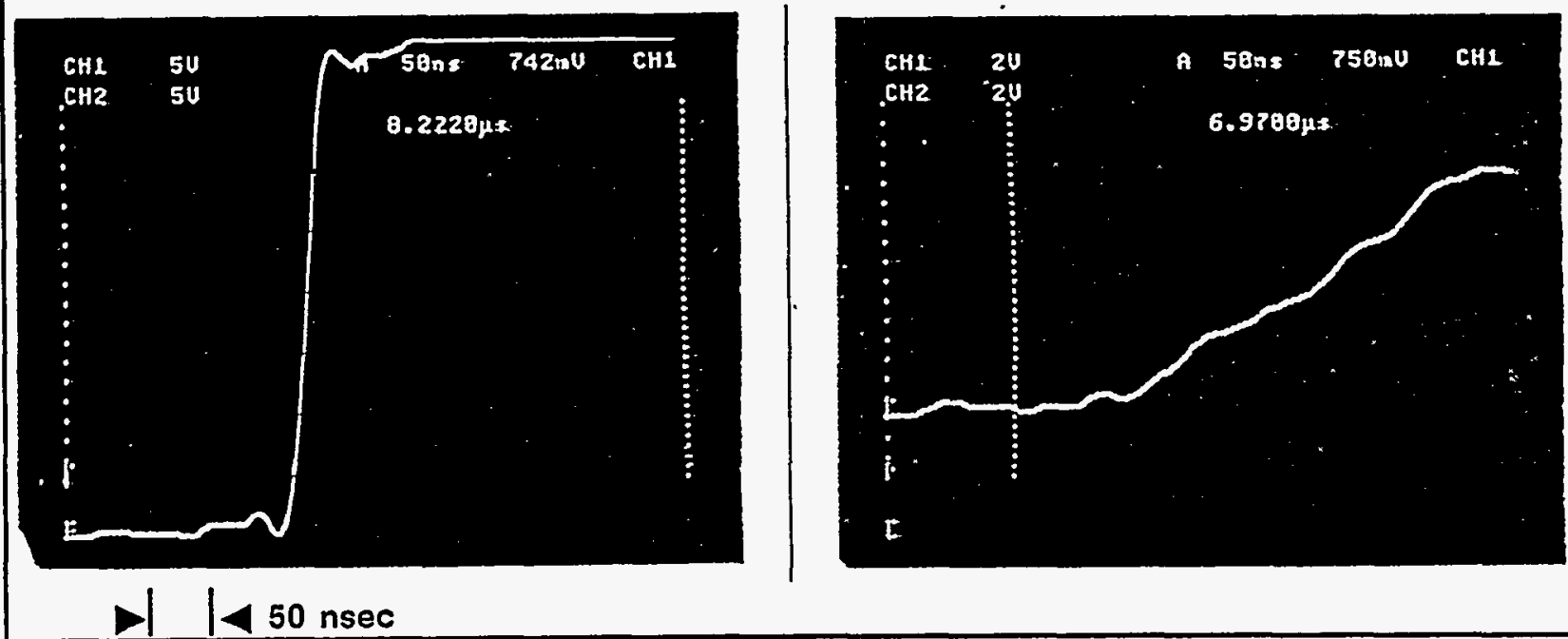

Figure 10 - Normal switch closure with ground is on the left. Switch closure without ground is on the right. Total separation was 2 in., resulting in 2-in. ground path.

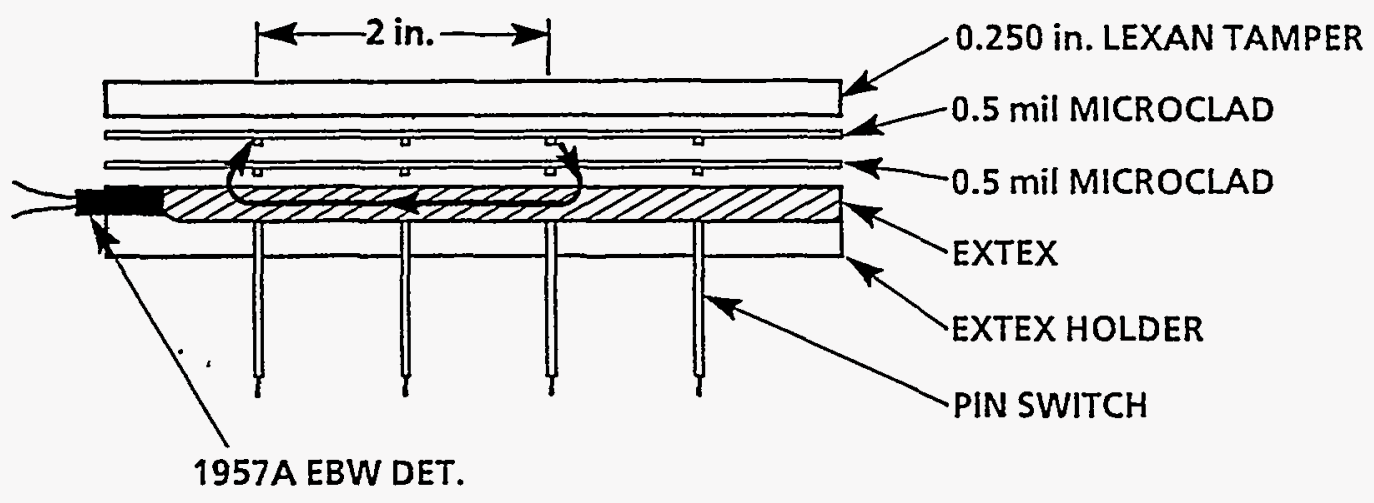

Figure 11 - Test device with 2-in. conduction path indicated. 


\section{Test Series 5: Effect of Kapton Removal Between S1 and S2}

In an effort to better understand the exact path of conduction, two additional tests were performed to compare the effect of Kapton removal between two switches. Removal of the Kapton would eliminate the path of shocked and/or charred Kapton and leave the detonation products and the shocked and charred Lexan and ABS plastic as other potential paths. The same test device was used as shown in Figure 4, except that a square piece of Kapton, approximately 0.75 in. by $0.75 \mathrm{in}$., was cut from the cable between the first two switches for the second test. In both cases the ground was not attached to the second switch. The first shot, shown at 500 nsec/division in the left trace of Figure 12, shows the closure of both $\mathrm{S} 1$ and $\mathrm{S} 2$ for the device with a switch/cable as used before. The second shot of this series used the modified cable that eliminated Kapton between the switches. The result of this shot is shown in the trace on the right side of Figure 12. A comparison of the two traces shows a dramatic difference in the amplitude of the response of $\mathrm{S} 2$.

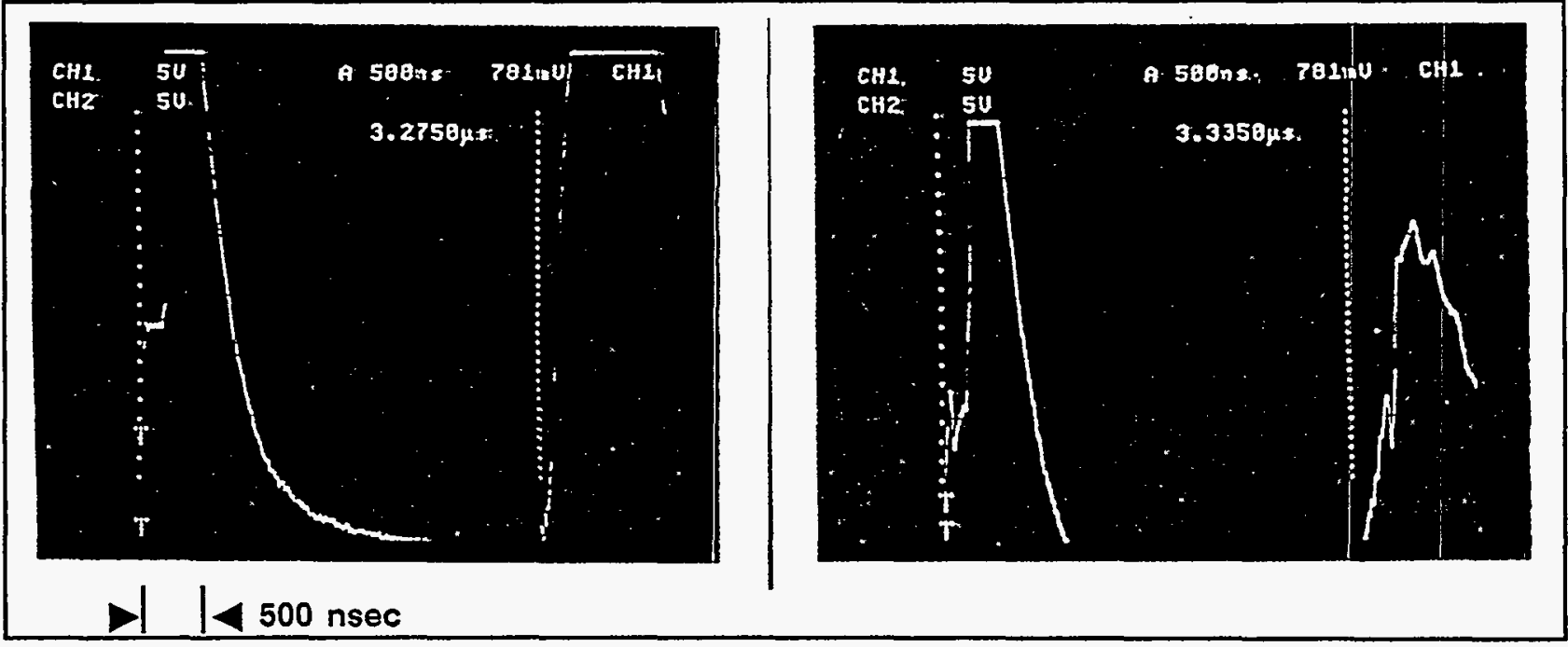

Figure 12 - Effect of Kapton removal between S1 and S2. Note low amplitude of second signal in trace at right (500 nsec/division).

\section{Early Conclusions}

- Multiple conduction paths exist.

- Post shocked/charred Kapton is a primary path to ground. 


\section{Conclusion}

Tests using a series of shock-induced Kapton switches have indicated a good correlation between ionization pin switch and shock switch closure. Test results indicate that the reason for the switching is shock conduction. Tests also show that the polarity of the switch had no influence on the switch performance. Also, the inherent time delay that was previously observed [1] was not seen in these tests, and the lower tangential shock pressures from detonating Extex were high enough to cause transition from an insulator to a conductor.

It was also found that a cover coat over the switch did not change the switch performance to any noticeable degree. When tested sequentially, there was interaction between the switches at high voltages. After the first switch closed, it made available to subsequent switches a second ground path. Interaction between switches was observed in all devices tested up to 2 in. apart. Removal of the Kapton reduced the cross talk between switches, but did not eliminate it, indicating multiple ground paths through the detonation products.

\section{Reference}

1. R. A. Graham, "Shock-Induced Electrical Switching in Polymeric Films," Megagauss Physics and Technology, ed. P. J. Turchi, Plenum Press, New York, 1980. 


\section{Distribution}

\section{EXTERNAL}

OSTI, UC-700 (58)

L. D. Kirkman, DOE/DAO

D. Mabry, Eglin Air Force Base

S. Smith, Eglin Air Force Base

\section{INTERNAL}

R. D. Cech (5)

J. C. Cheng

T. A. Demana

E. E. Egleston

J. Hobbs

L. D. Kirkman

J. J. Maher

T. D. Peeples

M. Robinson

D. R. Schaeffer

I. H. Schmidt

Library (5)

Technical Publications 